\title{
Implementation of MLC 2006 for Indonesian Seafarers: A Gap Analysis in Aspects of Health Care and Social Security of Seafarers on Board
}

\author{
Budi Purnomo, Imam Fachruddin, Antoni Arif Priadi, Damoyanto Purba, and April Gunawan \\ Sekolah Tinggi Ilmu Pelayaran Jakarta, Jakarta \\ e-mail: budi_purnomo@dephub.go.id
}

\begin{abstract}
Maritime workers are workers who are regulated internationally through the Maritime Labour Convention (MLC) 2006 which has been ratified by the Indonesian government through Law No. 15 of 2016. In the convention regulated aspects include health care on ships and land, social security, welfare facilities on land, access to seafarers' complaints, protection of health and safety, and accident prevention. This study aims to evaluate the application of the convention so far through the gap analysis method and index performance analysis (IPA). Gap analysis is used to get the difference between the performances and expectations of the respondents. To see the variables that need to be improved, maintained, not a priority for improvement or variables that are above expectation then used the IPA model. This research examines how seafarers' performances and expectations are related to the implementation of MLC in Indonesia, especially in the aspects of health care, social security, and welfare on board. The results show that almost all research variables suggest a gap although relatively small in value. First, it can be summarized that there are several variables that need to be improved such as Protection and health care, Hospitals on board, and complaints. These variable variables need to get attention for future improvements. There are several variables that need to be maintained such as visit a doctor, health, sick, disability, opportunity to use telephone and internet access, procedures for handling complaints, occupational health and safety (OHS), risk assessment, and safety meetings. Last, variables that are considered excessive in implementation should also get the attention that is medical publications, medical equipment, occupational health, and safety checks.
\end{abstract}

Keywords-Health Care, MLC, Social Security, Welfare Facilities.

\section{INTRODUCTION}

$\mathrm{T}$ HE Maritime Labour Convention 2006 (MLC) is an international agreement of the International Labour Organisation (ILO) which sets out seafarers' rights to decent conditions of work. As of January 2019, a total of 90 countries had ratified the MLC 2006, which has resulted in more than $91 \%$ of the world's shipping fleet being regulated.

In Indonesia, the regulation on maritime affairs is generally regulated in Government Regulation No. 7 of 2000 concerning Maritime Affairs. In 2016, the Indonesian government approved regulations No. 15 of 2016 concerning the Implementation of the MLC, 2006. The enactment of the MLC into Indonesian regulation resulted in all provisions of this convention being enforced in Indonesia.

There is a lot of research on seafarers, covering the field of maritime education [1][2][3][4][5], and [6], maritime control [7][8], maritime transport [9], seafarers [10], MLC [11][12]. This article examines how seafarers' performances and expectations are related to the implementation of MLC in Indonesia, especially in the aspects of health care, social security and welfare on board.

\section{LITERATURE REVIEW}

One factor that determines whether a rule goes well is the implementation of the rules in accordance with applicable regulations. This is represented by the level of satisfaction of someone who feels the application of these rules. The level of satisfaction of a person can be measured by comparing the performance with the expectations he feels [13]. Performance is the result of work both in quality and quantity achieved by a person in carrying out tasks according to the responsibilities given. Then hope is an estimate or belief about someone about what he will receive [4]. If performance meets expectations, the rules that are made are implemented well. Furthermore, if performance exceeds expectations, the rules are applied very well.

The currently popular service quality model is the service quality (SQ) model with the analysis used covering 5 categories, namely knowledge gap, standard gap, delivery gap, communications gap, and service gap. Gap analysis used in this study focuses on the service gap, which is the gap between perceived performance $(\mathrm{P})$ and expected service (E). The researcher wants to find out how big is the implementation of MLC 2006 for Indonesian seafarers in aspects of Health Care and Social Security of Seafarers on Board. The determination of dimensions in this study refers to the regulations in MLC 2006.

\section{RESULT AND DISCUSSION}

The method used in this research is quantitative descriptive. The sample consisting of 400 respondents, was selected by means of the accidental sampling technique. The technique is a type of nonprobability or non-random sampling where members of the target population that meet certain practical criteria, such as easy accessibility, geographical proximity, availability at a given time, or the willingness to participate are included for the purpose of the study [14]. It is also referred to the researching subjects of the population that are easily accessible to the researcher [15]. Convenience samples are sometimes regarded as 'accidental samples' because elements may be selected in the sample simply as they just happen to be situated, 
Table 1.

Description of variable based on MLC 2006

\begin{tabular}{|c|c|c|}
\hline & Description of Variable & Category \\
\hline V1 & Protection and health care are provided free of charge to all crew members & Medical Treatment \\
\hline $\mathrm{V} 2$ & The right to visit a doctor without delay at the port & \\
\hline V3 & Hospitals on board are clean, hygienic and are not used as cabins & \\
\hline V4 & Availability of medical equipment & \\
\hline V5 & Medical publications are available on board & \\
\hline V6 & A list of radio contacts for medical advice is available & \\
\hline V7 & Medical journals and health visit reports are available on board & \\
\hline V8 & Health care allowance & Seafarers Social Security \\
\hline V9 & Sick care & \\
\hline V10 & Disability care & \\
\hline V11 & Pension & \\
\hline V12 & Opportunity to cruise at the ports visited & Seafarers Welfare inshore \\
\hline V13 & Opportunity to use telephone and internet access at the port visited & \\
\hline V14 & The availability of procedures for handling complaints from seafarers & Seafarers Complain Access \\
\hline V15 & Each crew ship has a copy of the complaint procedure & \\
\hline V16 & Every complaint is recorded in a book prepared on board & \\
\hline V17 & Complaints are handled fairly, on time and effectively & \\
\hline V18 & There is a list of contacts from the state flag of the ship and the & \\
\hline V19 & authorities authorized from the country of origin of the seafarers & Health, Safety Protection and \\
\hline V20 & $\begin{array}{l}\text { Occupational Health and Safety (OHS) policies, procedures and programs are carried out } \\
\text { on board }\end{array}$ & Accident Prevention \\
\hline V21 & $\begin{array}{l}\text { Someone on board has been appointed to carry out Occupational Health and Safety (OHS) } \\
\text { policies, procedures and programs }\end{array}$ & \\
\hline V22 & Risk assessment is carried out and documented & \\
\hline V23 & Accidents and incidents have been investigated, reported and recorded & \\
\hline V24 & Safety meetings are regularly held & \\
\hline $\mathrm{V} 25$ & Seaman understands his responsibilities & \\
\hline V26 & Training on board and familiarization has been carried out & \\
\hline V27 & Implementation of work on the ship carried out safely & \\
\hline $\mathrm{V} 28$ & Personal protective equipment (PPE) available and suitable for related tasks & \\
\hline V29 & PPE is not in an expired condition and a replacement mechanism is available & \\
\hline V30 & $\begin{array}{l}\text { Measuring instruments to measure occupational health and safety risks are available on } \\
\text { board }\end{array}$ & \\
\hline V31 & Occupational Health and Safety checks and supervision are routinely carried out & \\
\hline
\end{tabular}

The survey was conducted at Sekolah Tinggi Ilmu Pelayaran Jakarta, Politeknik Ilmu Pelayaran Semarang, and Politeknik Pelayaran Surabaya during May to October 2019

GAP ANALYSIS FOR VARIABLES ON MEDICAL TREATMENT

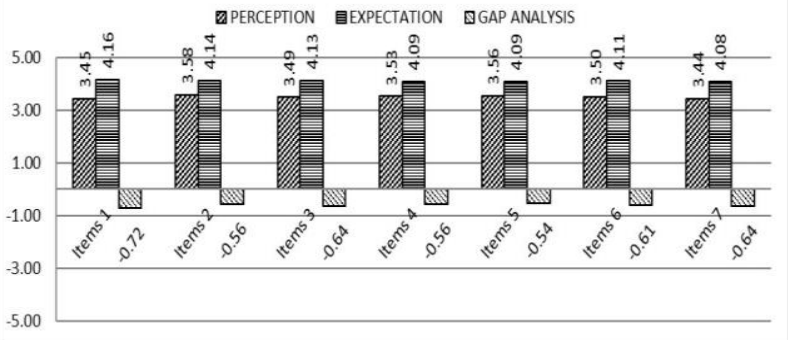

Figure 1. The gap analysis for dimension of medical treatment.

spatially or administratively, near to where the researcher is conducting the data collection.

The respondents were the seafarers who were identified proper to fill the questionnaires. The data were collected through questionnaires. The analysis used is the Gap Analysis and Index Performance Analysis (IPA) [16].

The questionnaire consists of general information of the respondent, that is age, education background, competency certificate degree and sea service. Then, the questions asked respondents to level the degree of performance and expectation of each variable. To extract the level of performance, the respondents were asked to rate each variable on the five-point using Likert scale, varying from "strongly unnecessary" (1) to "strongly necessary" (5). Whereas for the level of expectation, the Likert's five point scale will be used in which 1 is for "strongly unexpected" and 5 is "strongly expected". A questionnaire survey was designed into five categories. The detail of variables is arranged as displayed in the Table 1.

\section{A. Gap Analysis for Five Category based on MLC 2006}

First of all, this study started with the respondents' profile and is supported by demographic data. There are $84.76 \%$ of respondent age have less than 31 years, followed by $14.59 \%$ of respondent have middle age between 31-50 years and small percentage more than 51 years. Further, there are $41 \%$ respondents graduated from senior high school, $14.51 \%$ graduated from diploma, $43 \%$ graduated from bachelor, and $0.63 \%$ graduated from master. Based on certificate of competency (COC), 34.38\% of respondents were deck officer class III, $0.95 \%$ of respondents were deck officer class II, and $4.73 \%$ of respondents were deck officer class IV. The result of medical treatment categories is presented in Figure 1.

From Figure 1, it can be shown that the largest gap in V1, that is protection and health care are provided free of charge to all crew members. Thus, the expectation of respondent is higher than the implementation MLC in Indonesia. Further, the same procedure is applied for the seafarers social security as presented in Figure 2.

From Figure 2, it can be shown that the largest gap in V11 that is pensions. It means that the expectation of respondent is higher than the implementation MLC in Indonesia. The next gap analysis is applied for the seafarers welfare inshore. The result is presented in Figure 3. It can be shown that both variable have value -0.53 . Thus, the expectation of respondent is higher than the implementation MLC especially opportunity to cruise at the ports visited and opportunity to use telephone and internet access at the port visited. The gap analysis seafarers complaint access is 


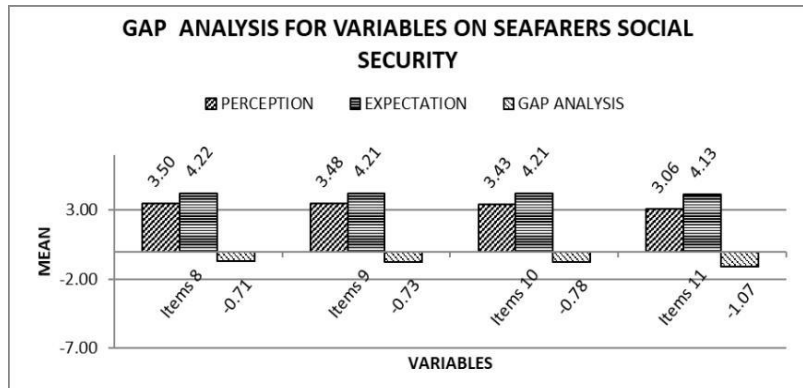

Figure 2. The gap analysis for dimension of seafarers social security.

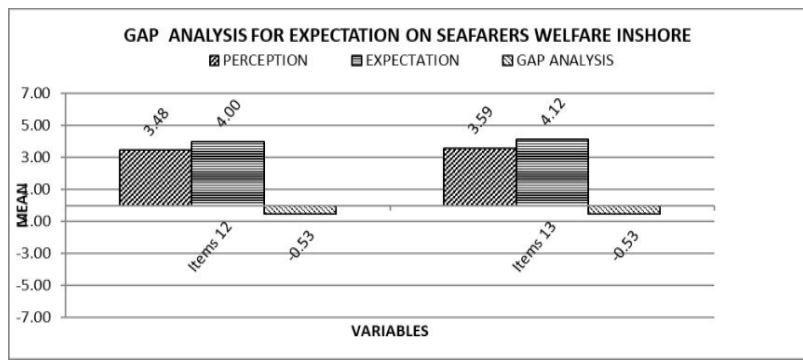

Figure 3. The gap analysis for dimension of seafarers welfare inshore.

presented in Figure 4. Figure 4 shows that the largest gap in V17 that is complaints are handled fairly, on time and effectively. The analysis gap of health, safety protection and accident prevention, is presented in Figure 5. Figure 5 shows that the largest gap in V28 that is Personnel protective equipment (PPE) is not in an expired condition and a replacement mechanism is available.

\section{B. Performance Analysis (IPA) for Five Category based on MLC 2006}

The result of analysis data with statistic software obtained Cartesian diagram on implementation MLC 2006 for medical treatment as shown on Figure 6.

The dimensions of medical treatment in Figure 6 for V1 and V3 fall within quadrant I. Their performance values are lower than their expectation. Then, dimensions of medical treatment for V2 fall into Quadrant II. This indicates that V2 are important to the respondent who have high performance related to the variables.

Next, the competency dimensions of V6 and V7 fall in quadrant III. This means that V6 and V7 is considered less important by the respondent and in fact its performance is not too special. The medical treatment for V4 and V5 fall in quadrant IV. The position of V4 and V5 according to the respondent has a low level of expectation but it has a good performance.

In Figure 7, the dimensions of seafarers social security for V8, V9, V10 fall in quadrant II. This condition must be maintained for the future as it is considered very important as well as the result is very satisfactory. Next, the competency dimensions of V11 fall in quadrant III. This means that V11 is considered less important by the respondent and in fact its performance is not too special.

According Figure 8, the of seafarers welfare inshore for V12 fall in quadrant III. Increased mastery over V12 needs to be reconsidered. The last competency dimensions of V13 fall in quadrant II. This indicates that V13 are important to the respondent who have high performance related to the variables.

Based on Figure 9, the dimensions of seafarers complain access for V17 fall into quadrant I. They are considered

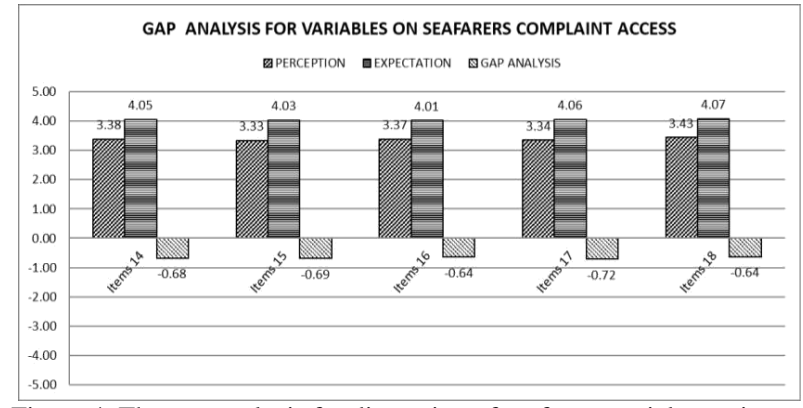

Figure 4. The gap analysis for dimension of seafarers social security.

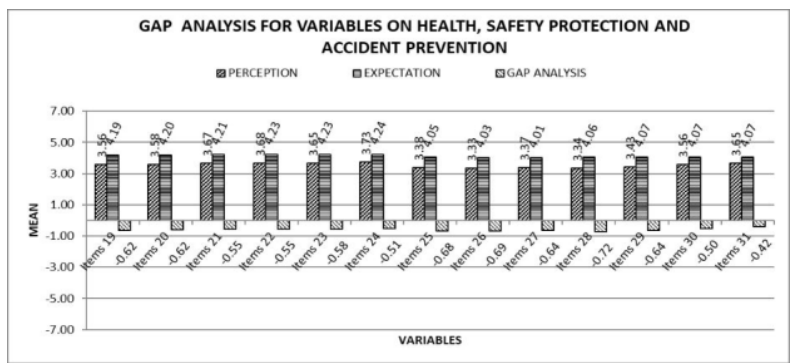

Figure 5. The gap analysis for dimension on health, safety protection and accident prevention.

important by respondents but they do not feel as they expect. Next, the variable of V14 and V18 fall into Quadrant II.

This condition must be maintained for the next time as it is considered expected and the result is very satisfactory. Next, V15 and V16 fall in quadrant III. V15 and V16 contained in quadrant III have low expectation level and its performance is also considered unfavorable by the respondent. Increased mastery needs to be reconsidered.

Based on Figure 10, the dimension of health, safety protection and accident prevention for V19, V20, V21, V22, V23 and V24 fall in Quadrant II. This condition must be maintained for the next time as it is considered expected and the result is very satisfactory.

Then, the variable V25, V26, V27, V28 and V29 fall in quadrant III. Increasing mastery of V25, V26, V27, V28 and V29 needs to be reconsidered. The last is the competency dimensions of V30 fall in quadrant IV. According to those, the respondent have low expectation but they have good performance.

\section{CONCLUSION}

Several things can be concluded in this research. The first relates to gap analysis showing that almost all research variables suggest a gap although relatively small in value. First, it can be summarized that there are several variables that need to be improved such as V1, V3, and V17. These variable variables need to get attention for future improvements. There are several variables that need to be maintained such as V2, V8, V9, V10, V13, V14, V8, V19, V20, V21, V22, V23, and V24.

Next, there are variables that also need to become attention by the respondents to increase the self-mastery such as V6, V7, V11, V12, V15, V25, V26, V27, V28 and V29. Last, variables that are considered excessive in implementation should also get attention. The variables are V4, V5, and V30.

\section{REFERENCES}

[1] S. Abila and L. Tang, "Trauma, post-trauma, and support in the 


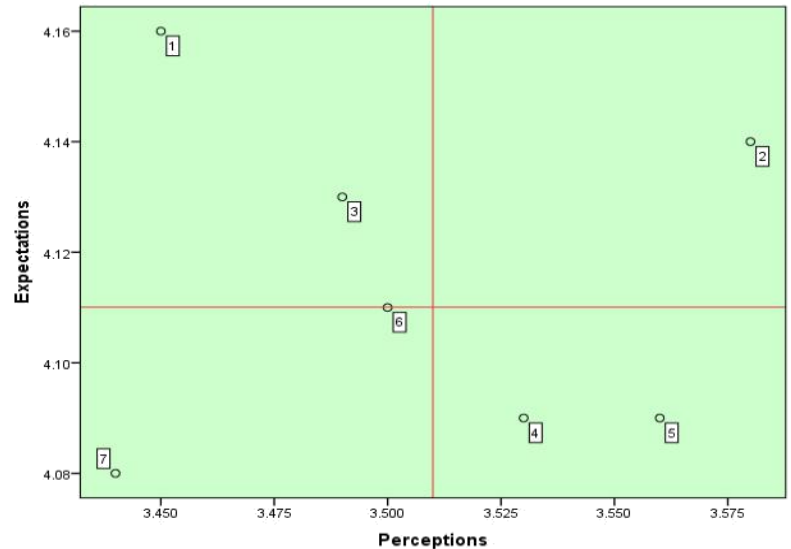

Figure 6. Cartesian diagram for medical treatment.

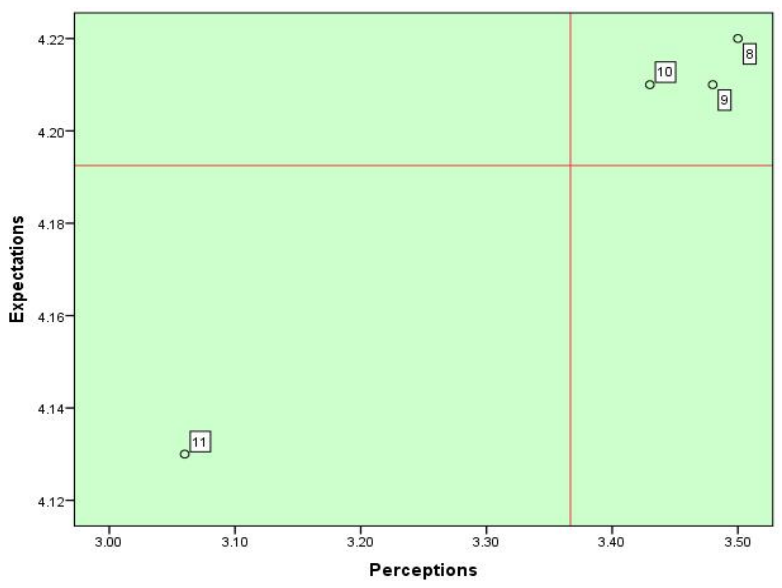

Figure 7. Cartesian diagram for seafarers social security.

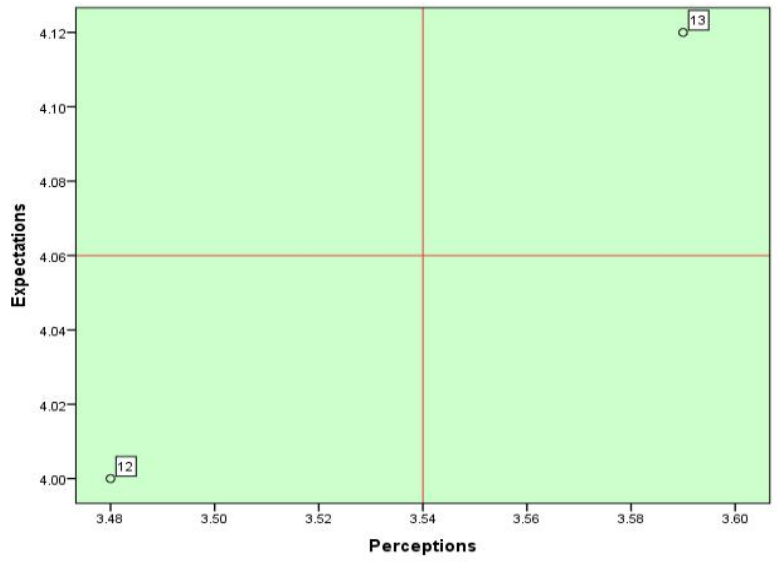

Figure 8. Cartesian diagram for seafarers welfare inshore.

shipping industry: The experience of Filipino seafarers after pirate attacks," Mar. Policy, vol. 46, no. 132, 2016.

[2] N. Acomi, "The Optimum Method of Students' Evaluation in Higher Education," Procedia-Social Behav. Sci., vol. 149, no. 4, 2014.

[3] O. Adăscăliței, "Ensuring the Rights of Ship-owners - Maritime Lien and Cesser Clause," Procedia - Soc. Behav. Sci., vol. 149, no. 14, 2014.

[4] O. Adăscăliței, "The Maritime Labour Convention 2006 - A Longawaited Change in the Maritime Sector," Procedia - Soc. Behav. Sci., vol. 149 , no. $14,2014$.

[5] L. Fan, J. Fei, U. Schriever, and S. Fan, "The communicative competence of Chinese seafarers and their employability in the international maritime labour market," Mar. Policy, vol. 83, no. 137,

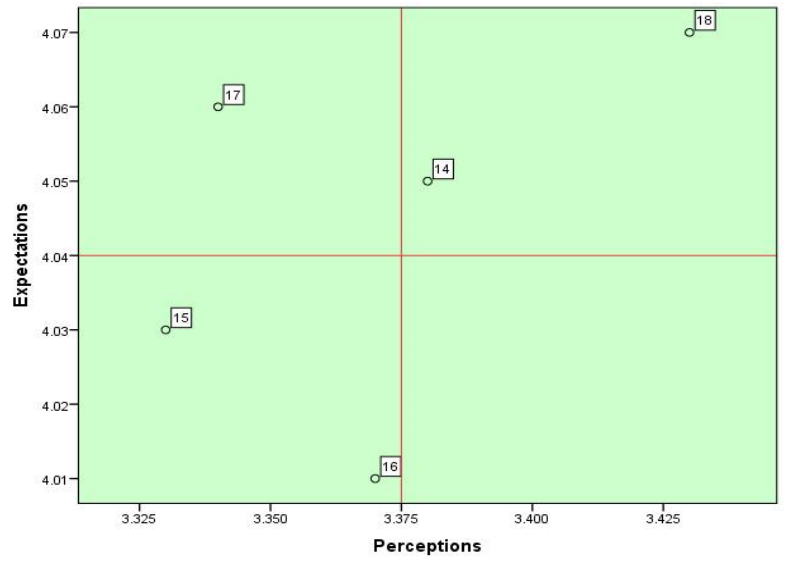

Figure 9. Cartesian diagram for seafarers complain access.

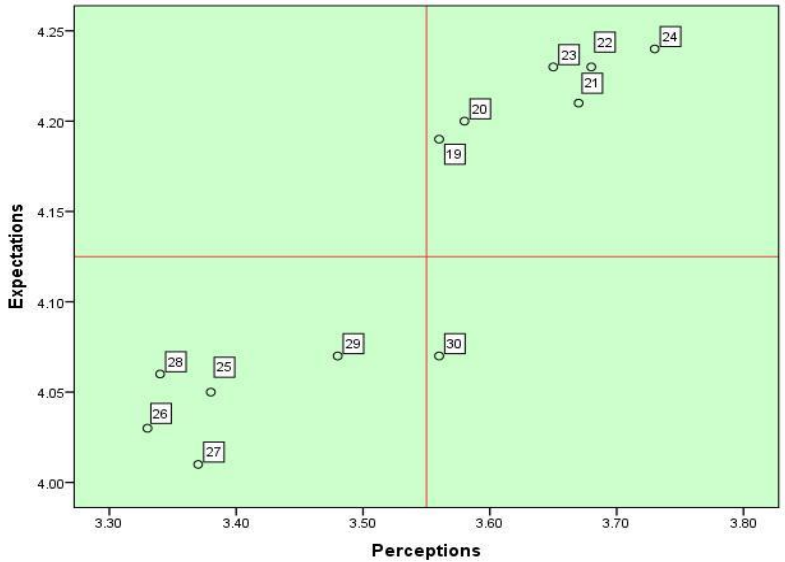

Figure 10. Cartesian diagram for dimension of health, safety protection and accident prevention.

2017.

[6] D. Featherstone, "Maritime labour and subaltern geographies of internationalism: Black internationalist seafarers' organising in the interwar period," Polit. Geogr., vol. 49, no. 7, 2015.

[7] B. Boockmann, "The effect of ILO minimum age conventions on child labor and school attendance: Evidence from aggregate and individual-level data," World Dev., vol. 38, no. 5, p. 679, 2010.

[8] E. Branten and A. Purju, "Estonia's Maritime Sector Stakeholder and their Reaction Patterns," Procedia - Soc. Behav. Sci., vol. 156, p. 227, 2014.

[9] E. Gagatsi, G. Giannopoulos, G. Aifantopoulou, and G Charalampous, "Stakeholders-based multi-criteria policy analysis in maritime transport: From theory to practice," Transp. Res. Procedia, vol. 22, p. 655, 2017.

[10] G. Chen and D. Shan, "Seafarers' access to jurisdictions over labour matters," Mar. Policy, 2017.

[11] K. Østermark Jensen and T. Leth, "On the doorstep to Maritime Labour Convention. How does it involve the maritime parties?" Arch. Des Mal. Prof. l'Environnement, vol. 74, no. 5, p. 572, 2013.

[12] W. J. Wu and D. Jeng, "Safety management documentation models for the maritime labour convention," Asian J. Shipp. Logist., vol. 28, no. 1, p. $41,2012$.

[13] C. Snyder, The Psychology Of Hope: You Can Get There From Here. New York: Free Press, 1994

[14] Z. Dörnyei, Research methods in applied linguistics. New York: Oxford University Press, 2007.

[15] G. Lisa, Convenience Sample. In The SAGE Encyclopedia of Qualitative Research Methods. Thousand Oaks: Sage Publications, 2008.

[16] M. Franklin, Performance Gap Analysis: Tips, Tools and Intelligence for Trainers. USA: ASTD Press, 2005. 